\title{
Gas transfer under breaking waves: experiments and an improved vorticity-based model
}

\author{
V. K. Tsoukala and C. I. Moutzouris \\ Laboratory of Harbor Works (LHW), School of Civil Engineering, National Technical University of Athens (N.T.U.A.), \\ 5 Iroon Polytechniou 15780 Zografou, Greece
}

Received: 29 July 2007 - Revised: 17 April 2008 - Accepted: 3 June 2008 - Published: 31 July 2008

\begin{abstract}
In the present paper a modified vorticity-based model for gas transfer under breaking waves in the absence of significant wind forcing is presented. A theoretically valid and practically applicable mathematical expression is suggested for the assessment of the oxygen transfer coefficient in the area of wave-breaking. The proposed model is based on the theory of surface renewal that expresses the oxygen transfer coefficient as a function of both the wave vorticity and the Reynolds wave number for breaking waves.
\end{abstract}

Experimental data were collected in wave flumes of various scales: a) small-scale experiments were carried out using both a sloping beach and a rubble-mound breakwater in the wave flume of the Laboratory of Harbor Works, NTUA, Greece; b) large-scale experiments were carried out with a sloping beach in the wind-wave flume of Delft Hydraulics, the Netherlands, and with a three-layer rubble mound breakwater in the Schneideberg Wave Flume of the Franzius Institute, University of Hannover, Germany.

The experimental data acquired from both the small- and large-scale experiments were in good agreement with the proposed model. Although the apparent transfer coefficients from the large-scale experiments were lower than those determined from the small-scale experiments, the actual oxygen transfer coefficients, as calculated using a discretized form of the transport equation, are in the same order of magnitude for both the small- and large-scale experiments. The validity of the proposed model is compared to experimental results from other researchers.

Although the results are encouraging, additional research is needed, to incorporate the influence of bubble mediated gas exchange, before these results are used for an environmental friendly design of harbor works, or for projects involving waste disposal at sea.

\footnotetext{
Correspondence to: V. K. Tsoukala

(v.tsoukala@hydro.civil.ntua.gr)
}

Keywords. Oceanography: general (Marine pollution) Oceanography: physical (Air-sea interactions) - Space plasma physics (Laboratory studies)

\section{Introduction}

The interest in the exchange of gases between the atmosphere and water bodies with its resultant effects on water quality starts from the beginning of the last century. Social interest in the exchange of greenhouse gases and pollutants between natural water bodies and the atmosphere over the past two decades has enhanced the interest of gas transfer across the air-water interface (Donelan et al., 2002). A wide range of the scientific community, from fluid dynamics experts to biochemists, are interested in studying and analyzing the complex processes controlling gas transfer.

The first studies on oxygen transfer through the air-water interface began from the rivers which expanded into the lakes and the oceans and lastly into estuaries and coastal seas due to the great impact of dissolved oxygen (D.O.) concentrations into aquatic organisms. Estuaries and coastal seas are important sources of oxygen, impacting regional or even tropospheric budgets (Kim and Andreae, 1992; Upstill-Goddard et al., 2000; Borges et al., 2003). Effects of seabed changes in the coastal zone and/or the presence of structures, make the study of natural flow hydrodynamics and the oxygenation of the sea-water due to the wave's action, even more complex.

The definition of air-sea oxygen concentration difference, $\Delta \mathrm{C}$, is in theory comparatively straightforward; however, due to inherent spatial and temporal inhomogeneity, obtaining the requisite spatial and temporal coverage of the coastal waters could be a significant challenge. An oxygen transfer coefficient or oxygen transfer velocity, $K_{L}$, is often used to express the rate of oxygen penetration through air-water interface, per unit of oxygen deficit. Accurately quantifying oxygen transfer velocity is potentially more problematic

Published by Copernicus Publications on behalf of the European Geosciences Union. 
than to define an oxygen concentration difference, because it is influenced by a wide range of environmental variables, most of which are strongly correlated. In the past several years substantial advances have been made in understanding the air-sea oxygen exchange, however, it is still insufficient to adequately parameterize many of the fundamental controlling processes (Upstill-Goddard, 2006).

Oxygen transfer in coastal waters is effected both through molecular and turbulent diffusion at the air-water interface and through bubble ebullition. Enhancements of oxygen transfer are expected as:

1. the microscale wave breaking initiated at wind speeds well below those associated with whitecaps (Csanady, 1990; Melville, 1996; Zappa et al., 2001),

2. the result of the turbulence generated by breaking waves (Kitaigorodskii, 1984; Woolf, 1995; Feddersen, 2005; Woolf et al., 2007),

3. the transfer across the surface of bubbles (Merlivat and Memery, 1983; Memery and Merlivat, 1985; Keeling, 1993; Woolf, 1993) and

4. the disruption of the surface microlayer by surfacing and bursting bubbles (Monahan and Spillane, 1984).

Waves and their associated velocity fields contribute to the oxygen transfer across the air-water interface in three principle ways: a) by increasing the surface area (often with the creation of bubbles); b) by providing transport and mixing of aerated fluid from the surface to the fluid bulk; and c) by thinning the highly aerated surface boundary layer. Thus, the primary role of the wave state is to provide a means for transport and mixing of the surface layer, via turbulence in the bulk until breaking waves occur.

Breaking waves at the ocean's surface inject bubbles and turbulence into the water column. During periods of rough weather the scales of wave breaking will increase with increasing sea states and result in mixing of the surface waters and the turbulent transport of bubbles to depth (Boettcher et al., 2000; Terrill et al., 2001; Melville and Matusov, 2002). It is expected that the creation of bubbles enhances $K_{L}$ by creating additional surface area and by enhancing the diffusion at the bubble's surface due to the increased pressure within the bubble. Plunging breaking waves at the coastal zone or in the vicinity of a coastal structure can entrain large masses of air bubbles when the top of the wave forms a water jet projecting ahead of the wave crest before impacting the coastal region.

Bubble induced oxygen transfer varies qualitatively depending on the size of the bubbles. According to Keeling (1993) three size regimes could be considered: 1) small bubbles with radius $(r) r<5 \times 10^{-5} \mathrm{~m}$ which completely disappear by dissolution in the water, 2) intermediate bubbles in which the gases equilibrate with gases dissolved in the water and 3) large bubbles with $r>5 \times 10^{-4} \mathrm{~m}$ in which oxygen is not in equilibrium with the water (Jahne et al., 1984; Memery and Merlivat, 1985). All three classes may be important in oxygen transfer. In particular, Keeling (1993) indicated that bubbles with a radius larger than $5 \times 10^{-4} \mathrm{~m}$, which have often been assumed to play a negligible role, contribute significantly to bubble induced oxygen transfer and supersaturation. Bubble-mediated gas transfer will support supersaturations of typically 1-2\% for oxygen (Woolf and Thorpe, 1991). Besides, bubble-mediated gas transfer was identified as the most significant contributor to gas exchange during wave breaking in an experimental gas exchange facility (de Leeuw et al., 2002; Garrettson, 1973). Bubble penetration depths $>16 \mathrm{~m}$ have been observed during wave breaking (Farmer et al., 1993) and the resulting change in bubble internal gas pressure drives gas transfer across the bubble-water interface, even though the gas partial pressure in surface water is at or near atmospheric equilibrium (Memery and Merlivat, 1985; Woolf and Thorpe, 1991; Woolf, 1993).

Up until now, many attempts to describe the gas transfer due to breaking waves and bubbles (e.g. Asher et al., 1996; Woolf, 1997; Asher and Wanninkhof, 1998) had been made, but the available data are still limited. The fraction of the ocean surface renewal by breaking waves per unit of time is found to be proportional to the cubic of the ten meter wind speed $\left(U_{10}\right)$ and is dominated by the shorter breaking waves (Melville and Matusov, 2002). The potential major impacts of vertical buoyancy fluxes due to air entrainment and bubbles are also unknown and have not been considered. Both the distribution and the dynamics of breaking-wave generated bubbles and turbulence, and their correlation are still poorly understood.

Lately, the environmental impact of coastal structures, and their impact in water quality in coastal areas force engineers to identify the effects of wave field, and wave breaking, in the coastal zone or/and in the vicinity of coastal structures, regarding oxygen transfer. Wave breaking in the vicinity of coastal structures results in high oxygenation rates and in water quality improvement of the surrounding area. Over recent years the prediction of the transfer coefficient as a function of the wave characteristics has been the focus of many researchers (Daniil and Moutzouris, 1995; Hosoi and Murakami, 1986; Hosoi et al., 1990; Kakuno et al., 1995).

According to the surface renewal theory (Higbie, 1935; Dankwerts, 1970), the oxygen transfer rate $\left(K_{L}\right)$ across the air-water interface is proportional to surface renewal rate. In practice, surface renewal is influenced by several variables, including free convection under calm conditions, wind induced mixing at low high wind speeds, changes in air-water momentum transfer due to drag, thermal stratification due to insolation, wave damping, buoyancy effects from precipitation and surfactants (Schluessel et al., 1997; Soloviev et al., 2002).

For gas transfer under breaking waves, Daniil and Moutzouris (1995) proposed a vorticity based renewal model with two different equations for breaking waves on a sloping 

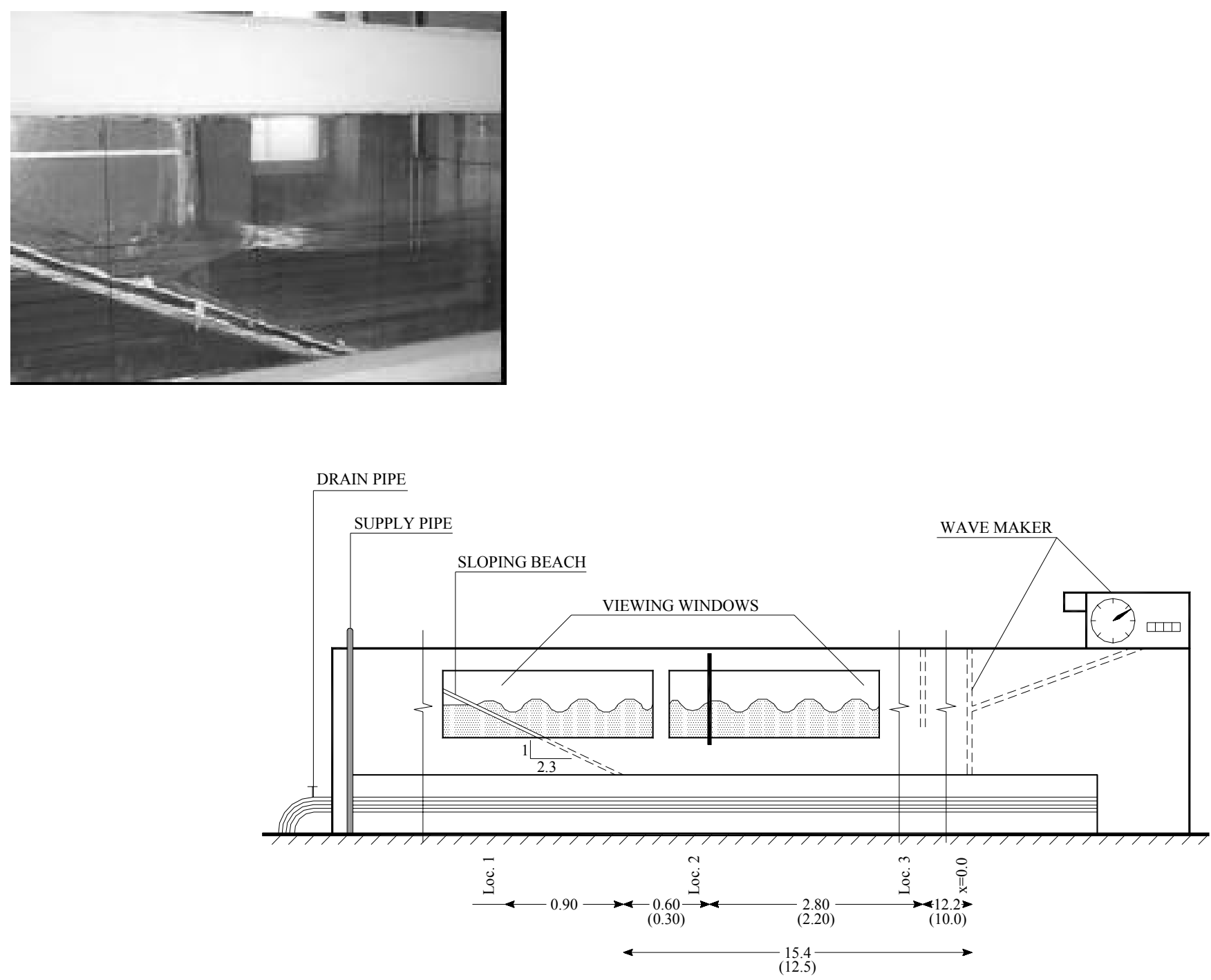

Fig. 1. Schematic plan view and experimental setup of the wave flume in LHW.

impermeable beach and for breaking waves on the breakwater. Their analysis concluded that the constants in the proposed equations are probably dependent on the slope of the beach and the type of the breakwater. Daniil et al. (2000) proved that there is no difference in the estimation of the oxygen coefficients if the horizontal flux through the permeable breakwater is not neglected.

Considering remarks from previous studies in this paper, a modified and improved vorticity-based renewal model for the prediction of gas transfer coefficient under breaking waves in the absence of wind forcing is proposed and fitted to experimental data obtained from both small- and large-scale experimental facilities. Although this analysis does not include bubble mediated transfer, which is dominant in the breaking of mechanically generated waves, the proposed model seems to represent the experimental data quite well.

\section{Experimental procedure}

Small-scale and large-scale oxygenation experiments under breaking and non-breaking waves were performed both with sloping beaches and rubble mound breakwaters at the wave flume of Laboratory of Harbor Works (LHW) and the Wind Wave Flume of Delft Hydraulics (DH). Additionally, largescale experiments were conducted with a three-layer rubble mound breakwater in the Schneideberg Wave Flume at Franzius Institute (FI). All the experiments conducted in the absence of wind forcing and currents.

The test method is based upon the removal of D.O. from the volume of water followed by re-oxygenation to a near saturation level, as described in the ASCE Standard (1993). For all the experiments D.O. is removed using nitrogen.

Water temperature and atmospheric pressure were recorded for the determination of the saturation 

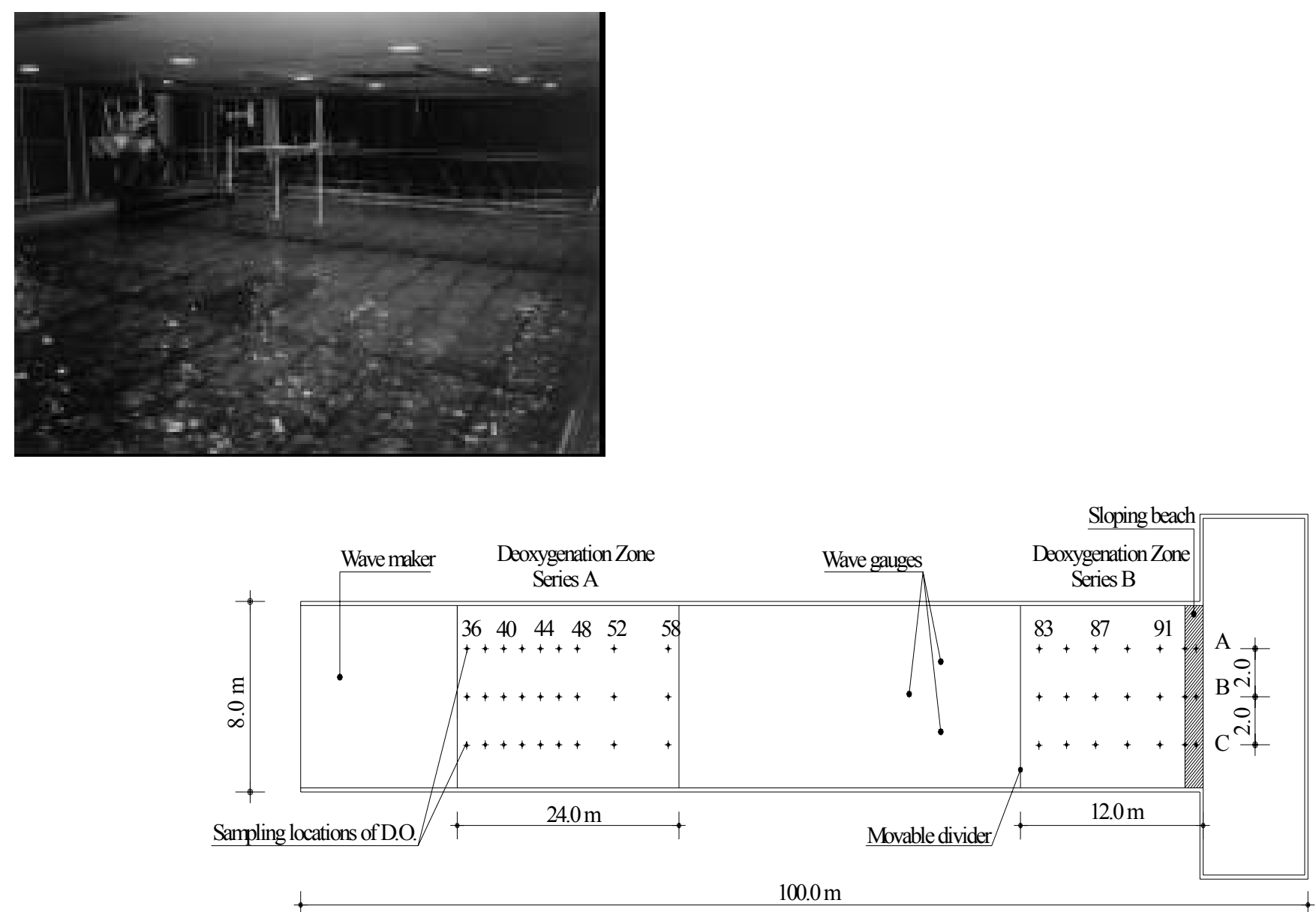

Fig. 2. Schematic plan view and experimental setup of the wind wave flume in DH.

concentration. D.O. - time histories were obtained for all experiments and sampling locations. To verify the accuracy of readings obtained with oxygen meters, water samples were also taken and analyzed using the azide modification of the Winkler titration method. Measurements of D.O. concentration commenced upon initial wave generation and continued until the D.O. value reached $\sim 80 \%$ of the estimated saturation level.

The wave flume of LHW is $27 \mathrm{~m}$ long, $0.60 \mathrm{~m}$ wide and $2 \mathrm{~m}$ deep (see Fig. 1). The flume is equipped with a mechanical wave generator. Monochromatic, sinusoidal waves with heights between $7.5 \times 10^{-2}$ and $23.4 \times 10^{-2} \mathrm{~m}$ and periods between 0.75 and $1.70 \mathrm{~s}$ were produced. The experimental procedure consisted of two distinct series of experiments. In the first series of experiments (Series LHW-V) a structure with a uniform slope of 1:2.3, was placed at the end of the flume to initiate wave breaking, while in the second series of experiments (Series LHW-A) a structure with a uniform slope of 1:5 was used. Three capacitance wave gauges were used to record the wave characteristics. The concentration of D.O. in the water was monitored over time by a portable
WTW OXI-196 oxygen meter, at 8 sampling locations along the flume.

The wave flume at DH is "T" shaped. It is $100 \mathrm{~m}$ long, $8 \mathrm{~m}$ wide and $1 \mathrm{~m}$ deep. The last $9 \mathrm{~m}$ section is $25 \mathrm{~m}$ wide (see Fig. 2). Waves with heights between $7.5 \times 10^{-2}$ and $28.3 \times 10^{-2} \mathrm{~m}$ and periods from 1.07 to $1.90 \mathrm{~s}$ were produced. The experimental procedure consisted of two distinct series of experiments. In the first series of experiments (Series DHA) waves were produced without any coastal structure in the flume. In the second series of experiments (Series DH-B) a concrete structure with a uniform slope of 1:2.3 was placed at the end of the flume, in order to initiate wave breaking. Three capacitance wave gauges were used to record the wave characteristics. The concentration of D.O. in the water over time was monitored by a portable, WTW OXI-196 oxygen meter, at 21 sampling locations along the flume.

The Schneideberg Wave Flume of the FI is $\sim 100 \mathrm{~m}$ long, $2 \mathrm{~m}$ wide and $2 \mathrm{~m}$ deep. During the experiments, about half of the flume length was used and isolated from the rest with a vertical watertight wooden wall. A three-layer breakwater model with $1: 1.5$ slope and $0.50 \mathrm{~m}$ long crest at $1.20 \mathrm{~m}$ above 


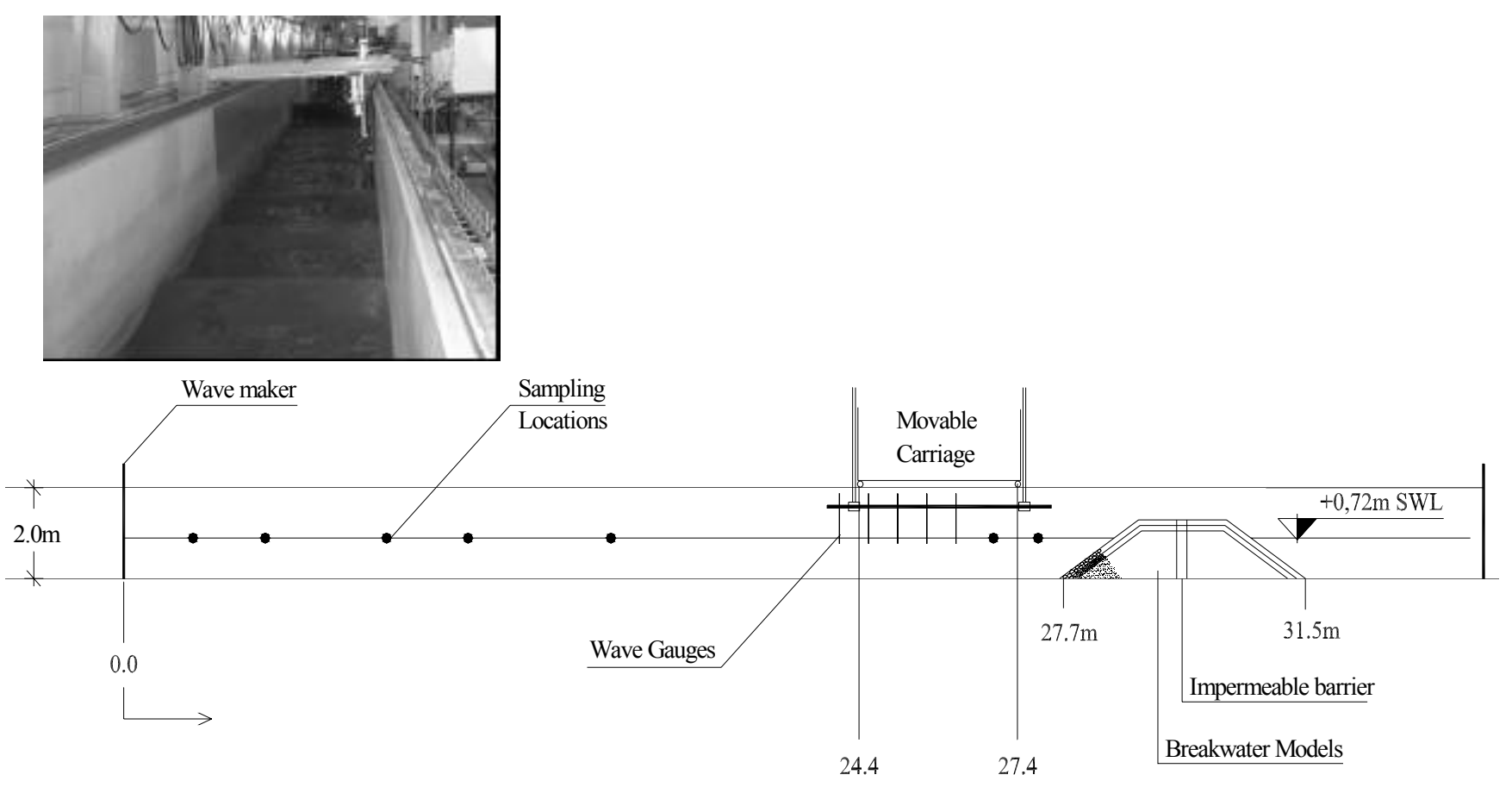

Fig. 3. Schematic cross section and experimental setup of the Schneideberg wave flume in FI.

bottom elevation was constructed at a distance of $27.75 \mathrm{~m}$ from the wave generator (see Fig. 3). Two different series of experiments were conducted. In the first series (Series FIA), the breakwater structure was impermeable with a wooden barrier placed in the middle of the breakwater body, prohibiting any transport through the structure. In the second series of experiments (Series FI-B), the wooden barrier was removed but the breakwater remained almost impermeable due to the layering of the structure. The wave height used in the experiments ranged from $9.2 \times 10^{-2}$ to $16.5 \times 10^{-2} \mathrm{~m}$, with wave periods from 1.11 to $1.43 \mathrm{~s}$. Five capacitance wave gauges were used to record the wave characteristics. The D.O. concentration at FI was monitored at 15 sampling locations by an YSI - Model 95 oxygen meter.

\section{Data analysis}

The transfer coefficient is determined indirectly through the mass transport equation, when the rest of the terms are known. The one-dimensional transport equation is usually used for analysis of data from laboratory flumes:

$$
\frac{\partial C}{\partial t}+U \frac{\partial C}{\partial x}=\frac{\partial}{\partial x}\left(D_{x} \frac{\partial C}{\partial x}\right)+S,
$$

where $C$ is the concentration of dissolved oxygen, $U$ is the mean velocity in the $\mathrm{x}$-direction $(U=0$ for the wave flume), $D_{x}$ is the longitudinal dispersion coefficient in the x-direction, $S$ is the source $(S>0)$ or sink $(S<0)$ term per unit volume and $t$ is time. Oxygen transfer through the air water interface can be expressed as a source term as:

$S=K_{L}\left(C_{S}-C\right) A_{S} / V$,

where $K_{L}$ is the oxygen transfer coefficient, $A_{S}$ is the average air-water surface area on the horizontal plane and $V$ is the aerated water volume extending from the free surface to the bottom of the flume.

If the only source term is the air-water gas transfer, and the terms for horizontal transport and dispersion are neglected, the transport equation is reduced to a first order differential equation.

For the initial conditions of $C=C_{0}$ at $t=0$, and assuming constant concentration for the entire experiment, the solution of Eq. (2) is as follows:

$$
C=C_{S}-\left(C_{S}-C_{0}\right) e^{-K_{L}\left(A_{S} / V\right) t} .
$$

Equation (3) can be expressed as a linear function of time as follows:

$$
\ln \left(C_{S}-C\right)=K_{L}\left(A_{S} / V\right) t+\ln \left(C_{S}-C_{0}\right) .
$$

The transfer coefficient is determined from Eq. (4) using linear regression and the measured D.O. concentrations.

The above solution is only valid for the case of a completely mixed fluid volume. If the source terms are not uniformly distributed, horizontal and diffusion terms are generated (Horsch, 1998; Daniil et al., 2000) and Eq. (3) is not applicable. In this case, the calculation of transfer coefficients requires a more detailed model. 
In this paper, the effect of increased longitudinal dispersion due to wave breaking on the structures has been considered in all the performed experiments. Equation (1) is discretized, using a control volume approach (Patankar, 1980). Integrating over a control volume of length $L_{i}$, volume $V_{i}$, cross sectional area $W$ (width of the channel) multiplied by the constant water depth $d$ and also assuming that $\partial C / \partial t$ and $S$ can be represented by their values at point $i$ and a linear profile between grid points for $\partial C / \partial x$, Eq. (1) can be written as:

$$
\begin{aligned}
V_{i} \frac{\partial C}{\partial t}= & \frac{D_{i, i+1}}{L_{i, i+1}} W d\left(C_{i+1}-C_{i}\right) \\
& -\frac{D_{i-1, i}}{L_{i-1, i}} W d\left(C_{i}-C_{i-1}\right)+V_{i} S_{i},
\end{aligned}
$$

where $L_{i, i+1}$ and $L_{i-1, i}$ are the distances, $D_{i, i+1}$, and $D_{i-1, i}$ are the horizontal diffusion coefficients between grid points $(i, i+1)$ and $(i-1, i)$, respectively.

In the experimental Series DH-A no longitudinal variation in D.O. concentration was observed. Therefore, Eq. (3) was used to determine the oxygen transfer coefficient. In Series $\mathrm{DH}-\mathrm{B}$, where the waves were breaking and longitudinal variation was observed, Eq. (5) describes the oxygen transfer coefficients that were determined based on the numerical scheme proposed by Tsoukala (2000). Five control volumes were used, with each control volume containing at least one sampling point. The system of equations described by Eq. (5) was solved numerically using the Tridiagonal Matrix Algorithm (Thomas, 1949) for the duration of each experiment. The initial concentrations measured at each sampling point were introduced in the computations. The gas transfer and diffusion coefficients were adjusted until a best-fit with observed D.O. values was obtained (Wanninkhof and Bliven, 1994). The same procedure was also followed in the experimental Series FI-A and FI-B, as well as in the experimental Series LHW-V and Series LHW-A, using 5 and 7 control volumes, respectively.

Transfer coefficients were normalized to $20^{\circ} \mathrm{C}$, assuming a square-root dependence on the Schmidt number $S c$, according to the equation given by Daniil and Gulliver (1988).

$\frac{K_{L 20}}{K_{L}}=\left[\frac{S c}{S c_{20}}\right]^{1 / 2}=\frac{v}{v_{20}}\left[\frac{293}{\theta+273}\right]^{1 / 2}\left[\frac{\rho}{\rho_{20}}\right]^{1 / 2}$,

where $S c=\nu / D v$ is the kinematic viscosity, $\theta$ is the water temperature in degrees Celsius and $\rho$ is water density. The subscript 20 denotes the values of the corresponding parameter at $20^{\circ} \mathrm{C}$ by the relations given by Heggen (1983).

Although Eq. (6) was derived for indexing gas transfer coefficients at water surfaces without significant air entrainment, it is in close agreement (less than 5\% difference in the $10-30^{\circ} \mathrm{C}$ range) with the indexing relation proposed by Gulliver et al. (1991). The indexing relation proposed by Gulliver et al. (1991) is theoretically based upon the velocity of a bubble suspended in a turbulent flow and the mass transfer across a bubble and also shows the $D^{1 / 2}$ dependence.
The experimental conditions, i.e. wave characteristics, water depth, water temperature and atmospheric pressure are summarized in Table 1. The actual transfer coefficients $K_{L}$, determined through Eq. (5) and the apparent transfer coefficients $K_{\text {Lap }}$, determined in Eq. (4), i.e. neglecting the horizontal flux, are also given for comparison purposes in Table 1 . The transfer coefficients calculated in Eq. (4) (see $K_{\text {Lap }}$ in Table 1) for large-scale experiments were lower than those in small-scale experiments, for experiments with the same wave characteristics, suggesting that oxygen transfer depends on the dimensions of experimental facilities (Tsoukala and Moutzouris, 1997; Tofa, 2000). Actual oxygen transfer coefficients, as computed from a discretized form of the transport equation and accounting for longitudinal dispersion, through Eq. (5), (see $K_{L}$ in Table 1) are found in the same order of magnitude for both small- and large-scale experiments (Tsoukala, 2000). Therefore, it is concluded that the developed horizontal flux should not be neglected during the calculation of actual transfer coefficients from experimental data, as it is proven that neighboring areas to the breaking zone experience substantially different gas transfer coefficients.

D.O.-time histories computed according to Eq. (5), as well as measured D.O. concentrations are shown in Fig. 4 for six different experiments. The initial condition is specified to match experimental data. Measured and predicted values are in good agreement, justifying the use of Eq. (5).

\section{Model formulation}

The first surface renewal model proposed by Dankwerts (1970) expresses the transfer coefficient as a function of the rate of surface renewal as follows:

$K_{L} \propto \sqrt{D_{m} r}$ or $K_{L} S c^{1 / 2} \propto \sqrt{v r}$,

where $K_{L}$ is the transfer coefficient, $D_{m}$ is the molecular diffusivity of the gas in water, $v$ is the kinematic viscosity of the water, $S c=v / D_{m}$ the Schmidt number and $r$ is the average surface renewal rate.

Daniil and Moutzouris (1995) presented a vorticity-based renewal model for gas transfer under breaking waves. The surface renewal rate was expressed as:

$r=\alpha_{r} \omega G_{r}$,

where $\alpha_{r}$ is a constant of proportionality and $\omega$ is the wave vorticity. The factor $G_{r}$ was expressed as $G_{r}=(L / d)^{2}$, where $d$ is the water depth and $L$ is the wave length, in order to incorporate the influence of relative depth. Current studies indicate that oxygenation increases with wave breaking intensity. It is therefore essential for the prediction of the gas transfer coefficient under breaking waves to incorporate in the $G_{r}$ factor a breaker type index to express the type of wave breaking. 
Table 1. Wave characteristics and corresponding transfer coefficients from the experiments.

\begin{tabular}{|c|c|c|c|c|c|c|c|c|c|c|c|c|c|}
\hline $\begin{array}{l}\text { Exp. } \\
\text { Series }\end{array}$ & $\begin{array}{l}\text { Exp. } \\
\text { No }\end{array}$ & $\begin{array}{l}T \\
\text { (s) }\end{array}$ & $\begin{array}{c}H \\
\left(\times 10^{-2} \mathrm{~m}\right)\end{array}$ & Structure & $\begin{array}{l}H_{b} \\
(\mathrm{~cm})\end{array}$ & $\begin{array}{c}L \\
(\mathrm{~m})\end{array}$ & $\begin{array}{l}L_{b} \\
(\mathrm{~m})\end{array}$ & $\begin{array}{c}\Theta \\
\left({ }^{\circ} \mathrm{C}\right)\end{array}$ & $\begin{array}{c}P \\
(\mathrm{mmHg})\end{array}$ & $\begin{array}{c}C_{S} \\
(\mathrm{mg} / \mathrm{l})\end{array}$ & $S c$ & $\begin{array}{c}\text { apparent } \\
K_{\text {Lap }} \times 10^{4} \\
(\mathrm{~m} / \mathrm{s})\end{array}$ & $\begin{array}{c}\text { actual } \\
K_{L} \times 10^{4} \\
(\mathrm{~m} / \mathrm{s})\end{array}$ \\
\hline LHW-V & $\mathrm{V} 2$ & 1.70 & 18.2 & SB1 & 27.40 & 3.77 & 2.61 & 23.2 & 747.5 & 8.39 & 464 & 0.48 & 1.06 \\
\hline LHW-V & V3 & 1.08 & 21.1 & SB1 & 24.39 & 1.80 & 2.11 & 25.6 & 749.0 & 8.03 & 412 & 3.14 & 302 \\
\hline LHW-V & V4 & 1.24 & 21.2 & SB1 & 26.23 & 2.31 & 2.22 & 24.4 & 752.0 & 8.21 & 437 & 2.59 & 3.56 \\
\hline LHW-V & V7 & 1.25 & 16.2 & SB1 & 21.56 & 2.34 & 1.87 & 26.2 & 748.0 & 7.98 & 400 & 2.30 & 1.76 \\
\hline LHW-V & V8 & 1.07 & 14.0 & SB1 & 17.87 & 1.77 & 1.52 & 26.6 & 747.5 & 7.87 & 393 & 1.82 & 2.19 \\
\hline LHW-V & V9 & 1.35 & 10.6 & SB1 & 16.25 & 2.66 & 1.58 & 25.2 & 748.5 & 8.09 & 420 & 1.31 & 1.38 \\
\hline LHW-V & V10 & 1.48 & 20.5 & SB1 & 27.97 & 3.08 & 2.46 & 25.2 & 749.0 & 8.09 & 420 & 2.28 & 2.58 \\
\hline LHW-V & V11 & 1.75 & 12.2 & SB1 & 20.57 & 3.92 & 2.21 & 25.4 & 749.0 & 8.06 & 416 & 0.30 & 1.60 \\
\hline LHW-V & V16 & 0.96 & 8.8 & SB1 & 11.92 & 1.43 & 1.05 & 25.2 & 748.5 & 8.09 & 420 & 0.77 & 2.34 \\
\hline LHW-V & V17 & 0.90 & 11.7 & SB1 & 14.31 & 1.26 & 1.21 & 25.6 & 747.0 & 8.01 & 412 & 1.55 & 3.75 \\
\hline LHW-V & V18 & 0.90 & 9.0 & SB1 & 11.79 & 1.26 & 1.01 & 25.5 & 747.0 & 8.01 & 414 & 1.04 & 2.52 \\
\hline LHW-A & $\mathrm{A} 1$ & 1.05 & 12.8 & SB2 & 14.81 & 1.71 & 1.30 & 21.5 & 743.0 & 8.61 & 505 & 1.06 & 0.71 \\
\hline LHW-A & $\mathrm{A} 2$ & 1.06 & 14.1 & SB2 & 16.02 & 1.74 & 1.39 & 18.4 & 746.0 & 9.20 & 593 & 1.55 & 2.57 \\
\hline LHW-A & A3 & 1.03 & 10.0 & SB2 & 12.15 & 1.64 & 1.11 & 18.3 & 742.0 & 9.17 & 596 & 0.55 & 0.72 \\
\hline LHW-A & A4 & 0.91 & 12.1 & SB2 & 13.23 & 1.29 & 1.13 & 16.4 & 742.0 & 9.54 & 660 & 1.41 & 1.29 \\
\hline LHW-A & A5 & 1.24 & 15.4 & SB2 & 18.43 & 2.31 & 1.66 & 16.8 & 742.0 & 9.46 & 646 & 1.28 & 1.14 \\
\hline LHW-A & A6 & 1.24 & 12.3 & SB2 & 15.57 & 2.31 & 1.47 & 18.5 & 746.0 & 9.19 & 590 & 0.84 & 0.68 \\
\hline LHW-A & A7 & 1.24 & 8.7 & SB2 & 12.02 & 2.31 & 1.23 & 18.9 & 748.0 & 9.13 & 578 & 0.51 & 0.51 \\
\hline LHW-A & A8 & 0.77 & 8.7 & SB2 & 9.49 & 0.93 & 0.81 & 19.3 & 745.0 & 9.02 & 566 & 1.43 & 1.45 \\
\hline LHW-A & A9 & 1.05 & 6.2 & SB2 & 8.59 & 1.71 & 0.88 & 18.6 & 744.5 & 9.15 & 587 & 0.33 & 0.43 \\
\hline DH-B & D8 & 1.07 & 7.0 & $S B 1$ & 10.62 & 1.77 & 0.54 & 18.3 & 752.0 & 9.30 & 596 & 0.25 & 0.27 \\
\hline DH-B & D9 & 1.13 & 8.0 & $S B 1$ & 12.06 & 1.96 & 0.62 & 18.0 & 759.0 & 9.44 & 606 & 0.34 & 0.58 \\
\hline FI-A & $\mathrm{F} 1$ & 1.11 & 15.6 & $I B$ & 21.42 & 1.91 & 0.46 & 13.3 & 728.0 & 10.10 & 782 & 1.25 & 1.46 \\
\hline FI-A & F2 & 1.43 & 12.7 & $I B$ & 20.97 & 2.92 & 0.45 & 15.3 & 711.0 & 9.35 & 701 & 0.67 & 0.76 \\
\hline FI-A & F3 & 1.43 & 15.7 & $I B$ & 18.46 & 2.92 & 0.53 & 15.5 & 711.0 & 9.32 & 693 & 0.80 & 0.90 \\
\hline FI-A & F4 & 1.11 & 13.2 & $I B$ & 18.30 & 1.89 & 0.41 & 15.7 & 714.0 & 9.32 & 686 & 0.68 & 0.76 \\
\hline FI-A & F5 & 1.11 & 16.5 & $I B$ & 20.37 & 1.89 & 0.47 & 11.7 & 724.0 & 10.33 & 856 & 1.04 & 1.17 \\
\hline FI-B & F6 & 1.43 & 13.0 & $P B$ & 23.96 & 1.89 & 0.40 & 12.9 & 722.0 & 10.01 & 800 & 0.58 & 0.65 \\
\hline FI-B & F7 & 1.43 & 15.3 & $P B$ & 23.40 & 2.92 & 0.52 & 13.5 & 717.5 & 9.83 & 774 & 0.69 & 0.82 \\
\hline FI-B & F8 & 1.43 & 9.2 & $P B$ & 16.04 & 2.92 & 0.35 & 13.9 & 715.0 & 9.70 & 757 & 0.76 & 0.21 \\
\hline FI-B & F9 & 1.11 & 13.5 & $P B$ & 21.37 & 1.89 & 0.47 & 14.5 & 725.0 & 9.71 & 732 & 0.41 & 0.47 \\
\hline
\end{tabular}

SB1: Sloping beach with slope 1:2.3, SB2: Sloping beach with slope 1:2.3, IB/PB: impermeable/permeable breakwater with a 1:1.5 sloping front,

Water depth: $d=0.72$ for LHW-V, and DH-B; $d=0.56$ for LHW-A and $d=0.80$ for FI 


\section{E XP LHWVV12}

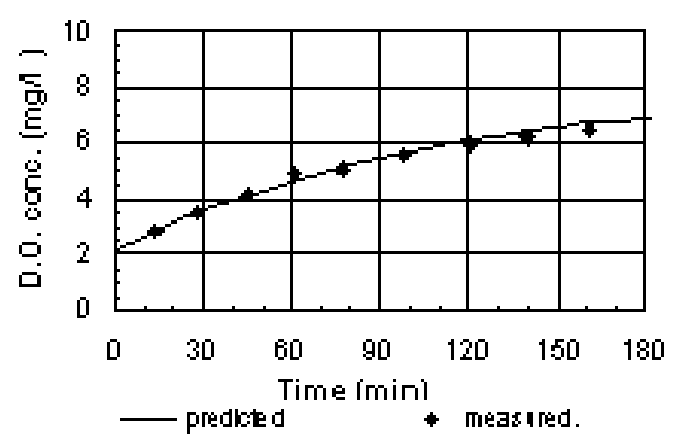

EXP LHWA A5

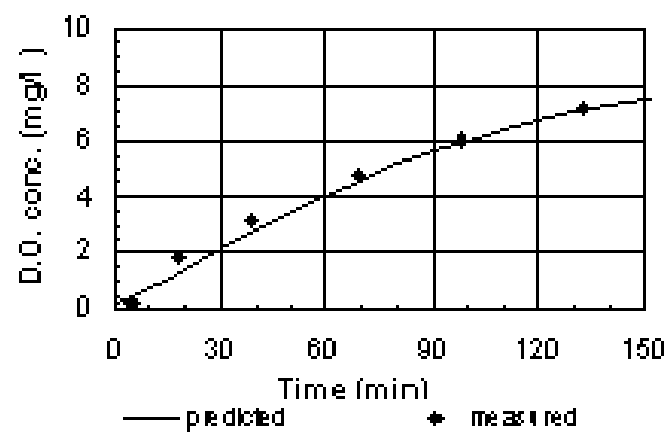

EXP DH-B D2

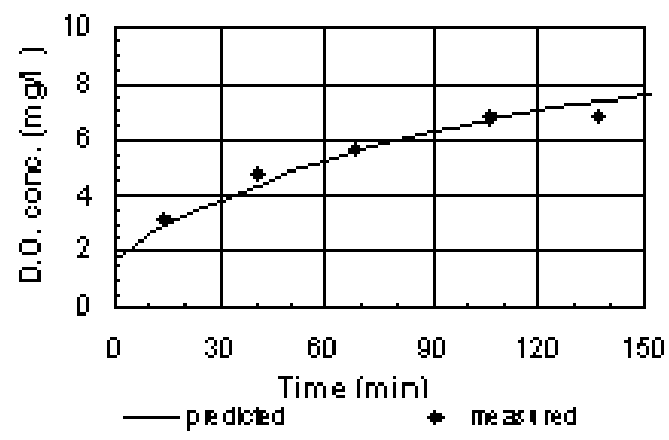

Fig. 4. Measured and predicted through Eq. (5) D.O. time histories.

Various dimensionless parameters have been examined (Tsoukala, 2000; Tsoukala et al., 2001), including the ones proposed by Irribaren (Irribaren et al., 1949), Galvin (Galvin, 1968), as well as the Wave Reynolds Number (Zhang and Sunamara, 1990), for incorporation into the surface renewal rate as an expression of the $G_{r}$ function. The Wave Reynolds Number $\left(R e_{w b}\right)$ for breaking waves was finally selected and the factor $G_{r}$ is now represented by the following equation:

$G_{r}=a \times R e_{w b}$,

where $a$ is a constant determined from the experimental results. $R e_{w b}$ is derived from the following equation (Zhang and Sunamura, 1990):
EXP LHWY V4

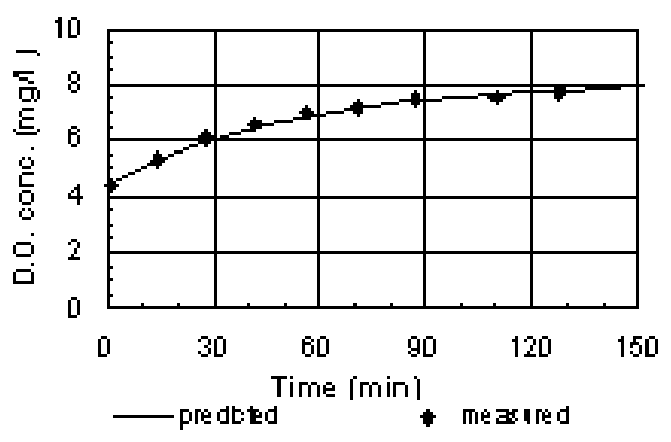

EXP பHWAAA8

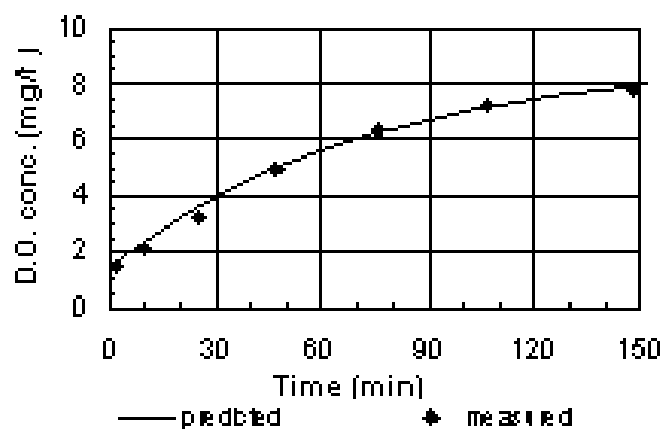

EXP DH- B D9

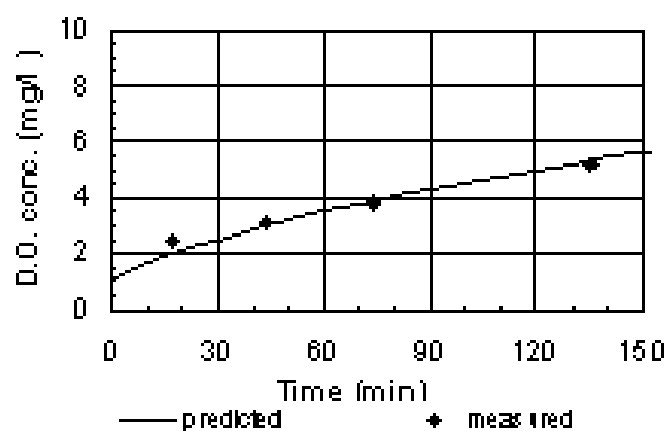

$R e_{w b}=\frac{H_{b} L_{b}}{\nu T}$

where $H_{b}$ and $L_{b}$ are the breaking wave height and length, respectively, and $T$ is the wave period. The wave heights in the breaking zone are calculated from the following equation of Le Mehaute and Koh (1967):

$H_{b} / H_{0}=0.76(\tan \alpha)^{1 / 7} \gamma_{o}^{-1 / 4}$

where $\gamma_{o}=H / L$ is the deep-water wave steepness and $\tan \alpha$ is the structure's slope. Wave lengths were computed from 
the equation suggested by the US Army Corps of Engineers (1990):

$L_{b}=T\left(g d_{b}\right)^{1 / 2}$,

where $d_{b}$ is the water depth at the breaking point.

Equations (9), (10) and (8) give the rate of surface renewal as follows:

$r=\alpha_{r} \omega R e_{w b}$.

And the following expression is finally derived for oxygen transfer coefficient:

$K_{L}=a_{r} \sqrt{D_{m} R e_{w b} \omega}$

or

$K_{L} S c^{0,5}=\alpha_{r} \sqrt{R e_{w b} v \omega}$.

The parameter $\alpha_{r}$ was found to be equal to 0.1 with the application of the least-squares method on the experimental values of $K_{L}$

$K_{L} S c^{0.5}=0.1 \sqrt{R e_{w b} v \omega}$.

The correlation coefficient of the experimental values of $K_{L}$ with the proposed equations results is particularly high $\left(R^{2}=0.78\right)$ compared to respective correlations published by Hosoi et al. (1977) and Daniil and Gulliver (1991). Oxygen transfer coefficients from the experimental measurements, as computed using Eq. (5), are compared to the proposed model of Eq. (16) in Fig. 5.

Further, the quantitative comparison between the vorticity model of Daniil and Moutzouris (1995) and the proposed modified vorticity model in the present paper was investigated by comparing the two statistical parameters of bias or distortion (b) and Root Mean Squared Error (RMSE) for each data set and for all the data sets that were used for Eq. (16). It is proven from the values of the statistical indicators in Table 2 that the modified model represents more accurately the experimental data.

The introduction of the Reynolds wave number for the prediction of the oxygen transfer coefficient in the proposed model is theoretically consistent, as it is based upon the assumptions by Aisa (1981), Daniil and Gulliver (1991) and George et al. (1995). The developed modified model presents an improved tool compared to the vorticity-based model of Daniil and Moutzouris (1995) with the introduction of the Reynolds number for breaking waves.

Besides considering that the temperature dependence and gas transfer is expressed through $S c^{1 / 2}$ it is believed that Eq. (30) can be used to describe the flow of various liquid phase controlled compounds. To succeed in this, as well as to infer from fresh water to salt water, it is required to examine the effect of bubbles entrained in the breaker zone on airwater oxygen transfer, as the bubble distributions are quite different between different gases and between the two types

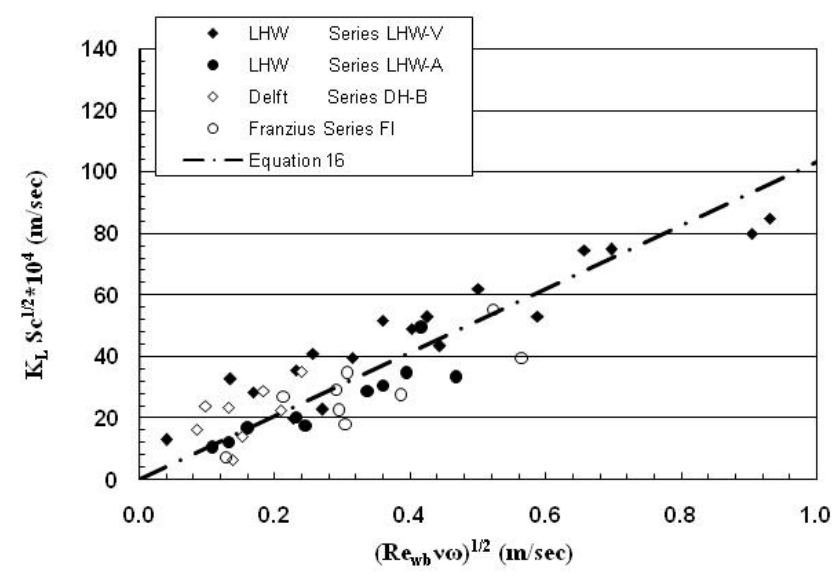

Fig. 5. Comparison of the transfer coefficients $K_{L}$, as computed from Eq. (5), with the proposed modified vorticity model of Eq. (16).

of water (Chanson, 1997; Chanson et al., 2006). According to the model proposed by Asher et al. (2002) the fractional contribution of bubbles to the total transfer velocity is limited to a maximum value of $25 \%$. The above prediction is consistent with accepted theories of bubble-mediated gas transfer, which state that bubble processes are less important for relatively soluble gases such as $\mathrm{O}_{2}$ and $\mathrm{CO}_{2}$ (Memery and Merlivat, 1985; Woolf, 1993).

Moreover, Eq. (16) could be used as a valid tool for the prediction of the oxygen transfer coefficient as a function of the wave characteristics.

\section{Comparison with literature data}

There are many sets of data published from experimental measurements performed for the determination of the oxygen transfer coefficient in water bodies. However, little experimental information exists on the effect of mechanically generated waves. Even less data had been published from measurements involving breaking waves on sloping sea bottoms and on coastal structures.

In Fig. 6, Eq. (16) is compared with results from experiments conducted by Kakuno et al. (1995) and Daniil and Moutzouris (1994) with breaking waves on a sloping, impermeable beach. Kakuno et al. (1995) performed experiments using a $20 \mathrm{~m}$ long, $50 \times 10^{-2} \mathrm{~m}$ wide and $50 \times 10^{-2} \mathrm{~m}$ deep wave flume, with a constant water depth of $30 \times 10^{-2} \mathrm{~m}$. A uniformly sloping bottom with a slope of 1:20 was placed at the one end of the flume and mechanical waves were produced with heights between $3.5 \times 10^{-2} \mathrm{~m}$ and $11.60 \times 10^{-2} \mathrm{~m}$ and periods between $0.88 \mathrm{~s}$ and $1.40 \mathrm{~s}$. The measurements by Kakuno et al. give values higher than Eq. (16).

The measurements by Daniil and Moutzouris (1995) were conducted on the same experimental facility as the smallscale measurements of the present study. Their beach slope 
Table 2. Statistical comparison of the present modified model and Vorticity model of Daniil and Moutzouris (1995).

\begin{tabular}{lcccc}
\hline \multirow{2}{*}{$\begin{array}{l}\text { Experimental } \\
\text { Series }\end{array}$} & \multicolumn{2}{c}{ Modified Vorticity Model } & \multicolumn{2}{c}{$\begin{array}{c}\text { Vorticity Model } \\
\text { Daniil and Moutzouris (1995) }\end{array}$} \\
\cline { 2 - 5 } & bias (m/s) & RMSE (m/s) & bias (m/s) & RMSE (m/s) \\
\hline Daniil and Moutzouris (1995) & 1.26 & 0.43 & 1.12 & 0.57 \\
LHW-V & 0.83 & 0.30 & 0.91 & 1.42 \\
LHW-A & 1.13 & 0.21 & 1.51 & 0.65 \\
DH-B & 0.86 & 0.52 & 0.35 & 1.08 \\
FI & 1.24 & 0.41 & 1.31 & 0.48 \\
All data of the present study & 0.99 & 0.36 & 1.08 & 0.94 \\
\hline
\end{tabular}

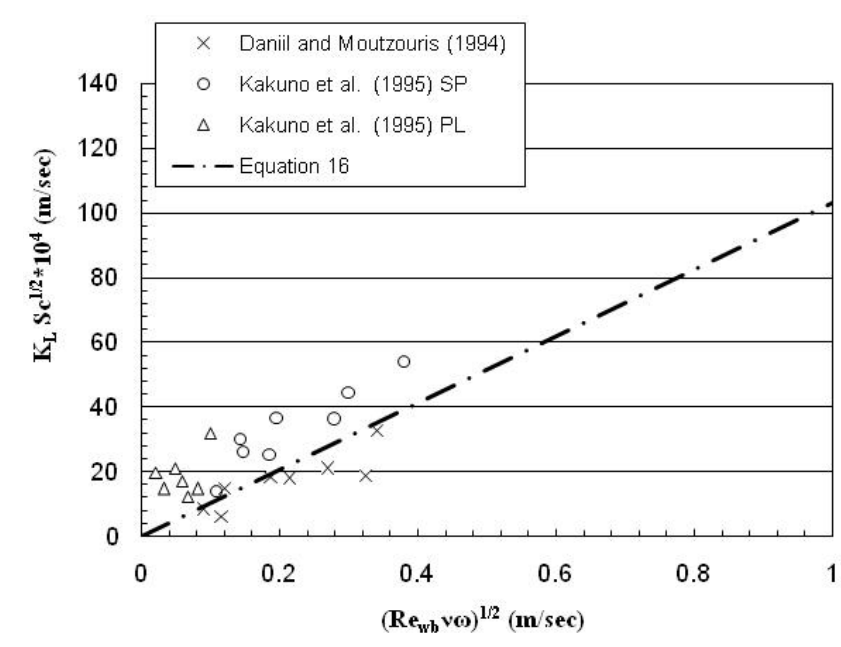

Fig. 6. Comparison of Eq. (16) with experimental data from impermeable sloping beaches (circles denote the results for the spilling break (SP), triangles denote the results for the plunging break (PL), of Kakuno et al. (1995) experiments).

was the same as in Series LHW-V, but with a different water depth. It is found that Eq. (16) is satisfactory for the oxygen transfer coefficient for various water depths and beach slopes.

In Fig. 7 results from experiments conducted in the vicinity of permeable and impermeable breakwaters by Daniil et al. (1998) are compared to Eq. (16). Their experiments were conducted in the wave flume of LHW, for three different water depths, namely $0.56 \mathrm{~m}, 0.76 \mathrm{~m}$ and $0.83 \mathrm{~m}$. Wave heights ranging between $5.60 \times 10^{-2} \mathrm{~m}$ and $20 \times 10^{-2} \mathrm{~m}$ and periods ranging between $0.75 \mathrm{~s}$ and $1.75 \mathrm{~s}$ were used. Although wave breaking on a rubble mound breakwater is less intense than on a sloping beach and, therefore, dissipation of energy is less significant, the oxygen transfer coefficients are rather well derived from the proposed equation.

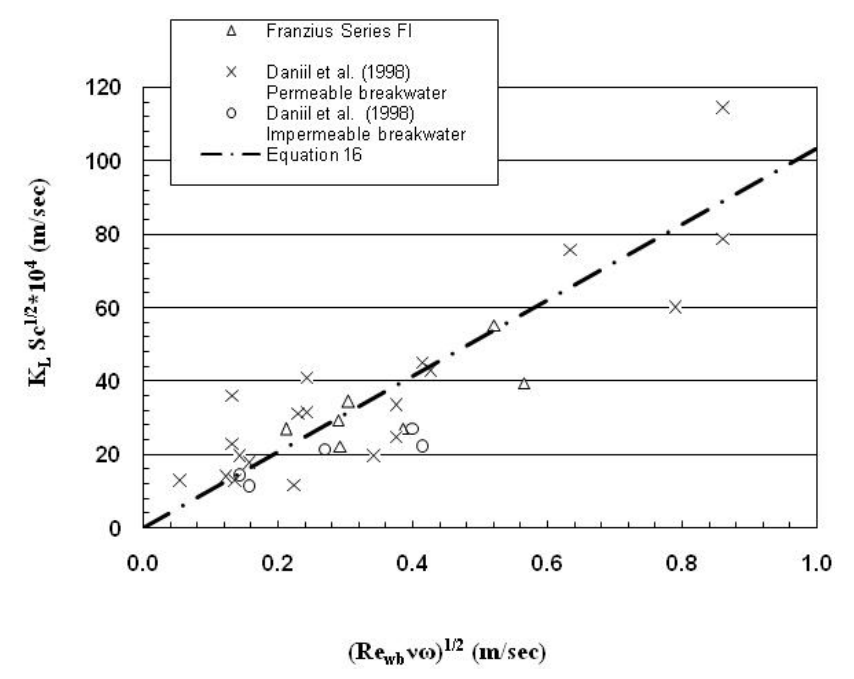

Fig. 7. Comparison of Eq. (16) with experimental data from the vicinity of rubble-mound coastal structures (crosses denote permeable breakwater and circles denote impermeable breakwater).

\section{Conclusions}

In the present paper the oxygen transfer coefficient is described with a surface renewal model. The rate of surface renewal in the area of a sloping beach depends on the wave characteristics and the slope of the beach. The model also describes the effect of turbulence on the water oxygenation. The rate of surface renewal is expressed as a function of the wave vorticity and the non-dimensional Reynolds number for breaking waves.

The proposed equation is considered as a satisfactory improvement of the vorticity based model proposed by Daniil and Moutzouris (1995), as the oxygen transfer coefficient is expressed independent of temperature conditions by eliminating the wave vorticity term. The model's empirical parameter $\alpha_{r}$ had been estimated from an adequate number of experimental measurements. These measurements have been 
conducted in experimental facilities of differing scales. The two models were further compared quantitatively by comparing bias estimator and root mean square errors for each data set and for all the data sets that are used for the prediction of Eq. (16).

It is also concluded after the comparison of the proposed equation with experimental data from the literature that it could describe with considerable accuracy the oxygen transfer mechanism under breaking waves in the vicinity of impermeable and permeable coastal structures.

In order to reduce scale effects, the model was validated with experimental data from measurements in both small and large-scale laboratory facilities. Although the results are encouraging, further measurements are now necessary to be made in nature and additional research is needed, to incorporate the influence of bubble mediated gas exchange.

Acknowledgements. The research was partly financed by the European Union, "Human Capital Mobility - Large Installations Program" (1994) for those experiments conducted in the Laboratory of Delft Hydraulics, The Netherlands, and "Training and Mobility of Researchers - Access to Large-Scale Facilities Program” (1999), for the experiment conducted at the Franzius Institute, University of Hanover, Germany. Measurements at the Laboratory of Harbour Works, National Technical University of Athens (LHW) were financed by the LHW. The authors would also like to acknowledge E. I. Daniil for her contribution during the setup of the experimental procedure and for her invaluable scientific aid for the integration of the present study.

Topical Editor S. Gulev thanks D. Woolf and another anonymous referee for their help in evaluating this paper.

\section{References}

Aisa, L., Caussade, B., George, J., and Masbernat, L.: Echanges de gaz dissous en écoulements stratifiés de gaz et de liquide, Int. J. Heat Mass Transfer, 24, 1005-1018, 1981.

ASCE: Standard, Measurement of oxygen transfer in clean water, ASCE, New York, USA, 1993.

Asher, W., Edson, J., McGillis, W., Wanninkhof, R. H., D. T., and Liitchendorf, T.: Fractional area whitcap coverage and air sea gas transfer velocities measured during GasWx-98, Iin: Gas Transfer at Water Surfaces, Geophys. Monogr., 127, 199-203, 2002.

Asher, W. E., Karle, L. M., Higgins, B. J., Farley, P. J., Monahan, E. C., and Leifer, I. S.: The influence of bubble plumes on air-water gas transfer velocities, J. Geophys. Res., 101, 12 027-12 041, 1996.

Asher, W. E. and Wanninkhof, R.: The effect of bubble-mediated gas transfer on purposeful dual-gaseous tracer experiments, J. Geophys. Res., 103, 10 555-10 560, 1998.

Boettcher, E. J., Fineberg, J., and Lathrop, D. P.: Turbulence and Wave Breaking Effects on Air-Water Gas Exchange, Phys. Rev. Lett., 85(9), 2030-2033, 2000.

Borges, A. V., Djeenidi, S., Lacroix, G., Théate, J., Delille, B., and Frankignoulle, M.: Atmospheric $\mathrm{CO}_{2}$ flux from mangrove surrounding waters, Geophys. Res. Lett., 30, 1558, doi:10.1029/200GL01143, 2003.
Chanson, H.: Air Bubble Entrainment in Free surface Turbulent Shear Flows, London, Academic Press, 1997.

Chanson, H., Aok, S., and Hoque, H.: Bubble entrainment and dispersion on plunging jet flows: Freshwatervs. Seawater, J. Coastal Res., 22(3), 664-677, 2006.

Csanady, G. T.: The role of breaking wavelets in air-sea gas transfer, J. Geophys. Res., 95, 749-759, 1990.

Daniil, E. I. and Gulliver, J. S.: Temperature dependence of the liquid film coefficient for gas transfer, J. Environ. Eng., ASCE, 114(5), 1224-1229, 1988.

Daniil, E. I. and Gulliver, J. S.: The influence of waves on air-water gas transfer, J. Environ. Eng., ASCE, 117(5), 522-540, 1991.

Daniil, E. I. and Moutzouris, C. I.: A vorticity-based model for gas transfer under breaking waves, Ann. Geophys., 13, 1039-1046, 1995 , http://www.ann-geophys.net/13/1039/1995/.

Daniil, E. I., Tsoukala, V. K., and Moutzouris, C. I.: Harbor Basin Seawater Oxygenation through Rubble Mound Breakwater Structures, J. Mar. Environ. Eng., 4(4), 277-300, 1998.

Daniil, E. I., Tsoukala, V. K., and Moutzouris, C. I.: The Beneficial Role of Rubble Mound Coastal Structure on Seawater Oxygenation, Ann. Geophys., 1360-1371, 2000.

Dankwerts, P. V.: Gas Liquid Reaction, Mc Graw-Hill Book Company, New York, USA, 1970.

de Leeuw, G. and Cohen, L. H.: Bubble size distribution on the North Atlantic and North Sea, in: Gas Transfer at Water Surfacrs, edited by: Donelan, M. A., Drennan, W. M., Saltzman, E. S., and Wanninkhof, R., AGU, Washington, D.C., 271-277, 2002.

Donelan, M. A., Drennan, W. M., Saltzman, E. S., and Wanninkhof, R.: Gas transfer at Water Surfaces, Geophys. Monogr., 127, AGU Washington, D.C., 2002.

Farmer, D. M., McNeil, C. L., and Johnson, B. D.: Evidence for the importance of bubbles in increasing air-sea flux, Nature, 361, 620-623, 1993.

Feddersen, F. and Trowbridge, J. H.: The Effect of Wave-breaking on Surfzone Turbulence and Alongshore Currents: A Modeling Study, J. Phys. Oceanogr., 35, 2187-2203, 2005.

Galvin, C. J.: Breaker type classification on three laboratory beaches, J. Geophys. Res., 73(12), 3651-3659, 1968.

Garrettson, G.: Bubble transport theory with application to the upper ocean, J. Fluid Mech., 59, 187-206, 1973.

George, J., Caussade, B., and Masbernat, L.: Conceptual modeling of interfacial Gas-liquid mass transfer, Selected papers from the 3rd International Symposium on Air-Water Gas Transfer, in: Air Water Gas Transfer, edited by: Jähne, B. and Monahan, E. C., AEON, Germany, 69-78, 1995.

Gulliver, J. S., Thene, J. R., and Rindels, A. J.: Indexing gas transfer in self aerated flows, ASCE, J. Environ. Eng., 116(3), 503-523, 1991.

Heggen, R. J.: Thermal dependent physical properties of water, J. Hydraul. Eng., ASCE, 109(2) 298-302, 1983.

Higbie, R.: The rate of absorption of a pure gas into a still liquid during short periods of exposure, Trans. Am. Inst. Chem. Engineers, 31, 365-390, 1935.

Horsch, G. M.: Steady, diffusive - reactive transport in shallow triangular domains, J. Eng. Mech., ASCE, 124(10), 1135-1141, 1998.

Hosoi, Y., Ishida, A., and Imoto, K.: Study on reaeration by waves, Coastal Engineering in Japan, 20, 121-127, 1977. 
Hosoi, Y. and Murakami, H.: Effect of breaking waves on dissolved oxygen and organic matter, Proceedings of the 20th Coastal Engineering Conference, Chapter 184, CER Council ASCE, Taipei, Taiwan, 2498-2512, 1986.

Hosoi, Y., Murakami, H., and Mitsui, H.: Reaeration due to wave breaking at coastal structures, Coastal Engineering in Japan, 33(1), 89-100, 1990.

Irribaren, C. R. and Nogales, C.: Protection des ports, XVII, International Navigation Congress, Section II, Comm. 4, Lisbon, 27-47, 1949.

Jahne, B., Wais, T., and Barbaras, M.: A new optical measuring device: A simple model for bubble contribution to gas exchange, in: Gas Transfer at Water Surfaces, edited by: Brutsaert, W. and Jirka, B. H., D. Reidel, Hingman, MA, 237-246, 1984.

Kakuno, S., Saitoh, M., Nakata, Y., and Oda, K.: The air-water oxygen transfer coefficients with waves determined by using a modified method, in: Air-Water Gas Transfer, Air-Water Gas Transfer, edited by: Jähne, B. and Monahan, E. C., AEON, Germany, 577-587, 1995.

Keeling, R. F.: On the role of large bubbles in air-sea gas exchange and supersaturation in the ocean, J. Mar. Res., 51, 237-271, 1993.

Kim, K. H. and Andrae, M. O.: Carbon disulfide in the estuarine, coastal and oceanic environments, J. Mar. Chem., 40, 179-197, 1992.

Kitaigorodskii, S.: On the fluid dynamical theory of turbulent gas transfer across an air-sea interface in the presence of breaking wind waves, J. Phys. Oceanogr., 14, 960-972, 1984.

LeMehaute, B. and Koh, R. C. Y.: On the breaking of waves arriving at an angle to the shore, J. Hydraul. Res., 5(1), 67-88, 1967.

Melville, W. K.: The role of surface wave breaking in air-sea interaction, Ann. Rev. Fluid Mech., 28, 279-321, 1996.

Melville, W. K. and Matusov, P.: Distribution of breaking waves at the ocean surface, Lett. Nature, 417, 58-63, 2002.

Memery, L. and Merlivat, L.: Modeling of the gas flux through bubbles at the air-water interface, Tellus, Ser. B, 37, 272-285, 1985.

Merlivat, L. and Memery, L.: Gas Exchange across an air-water interface: experimental results and modeling of bubble contribution to transfer, J. Geophys. Res., 88, 707-724, 1983.

Monahan, E. C. and Spillane, M. C.: The role of Whitecaps in airsea gas exchange, in: Gas Transfer at Water Surfaces, edited by: Brutsaert, W. and Jirka, G. H., Reidel, Dordrecht, The Netherlands, 495-503, 1984.

Patankar, S. V.: Numerical heat transfer and fluid flow, McGraw Hill, New York, USA, 1980.

Schluessel, P., Emery, W. J., and Soloviev, A. V.: Cool and freshwater skin of the ocean during rainfall, Bound.-Lay. Meteorol., 82, 473-482, 1997.

Smith, R. L.: Ecology and Field Biology, 4th edition, Harper Collins Publishers New York, 1990.

Soloviev, A., Edson, J., McGillis, W., Schluessel, P., and Wanninkhof, R.: Fine thermohaline structure and gas-exchange in the near surface layer of the ocean during GasEx-98, in: Gas Transfer at Water Surfaces, edited by: Donelan, M. A., Drennan, W. M., Saltzman, E. S., and Wanninkhof, R., AGU, Washington, D.C., 181-185, 2002.
Terrill, E. J., Melville, W. K., and Stramski, D.: Bubble entrainment by breaking waves and their influence on optical scattering in the upper ocean, J. Geophys. Res., 106(C8), 16815-16823, 2001.

Thomas, L. H.: Elliptic Problems in Linear Difference Equations over a Network, Watson Scientific Computing Laboratory, Columbia University, New York, 1949.

Tofa, E.: Large-scale experimental measurements at the Franzius Institute at the University of Hanover in Germany, for the oxygenation in the vicinity of breakwater, Diploma Thesis, National Technical University of Athens, Athens, 2000.

Tsoukala, V. K.: Wave induced sea water oxygenation at the coastal zone, Doctoral Dissertation, National Technical University of Athens, Athens, 2000.

Tsoukala, V. K. and Moutzouris, C. I.: Scale effects in oxygenation in the breaker zone of coastal structures, in: Coastal Engineering 1996, ASCE, 1, 403-414, 1997.

Tsoukala, V. K., Daniil, E. I., and Moutzouris, C. I.: Positive effects of Coastal Structures on water quality, in: XXIX IAHR Congress Proceedings, Thinghua University Press, Theme B, Environmental Hydraulics and Eco Hydraulics, 163-168, 2001.

Upstill-Goddard, R. C.: Air-sea gas exchange in the coastal zone, Estuarine Coastal and Shelf Science, 70, 388-404, 2006.

US Army Corps of Engineers: Laboratory study on macro-features of wave breaking over bars and artificial reefs, Technical Report CERC 90-12, CERC Waterways Experimental Station, Vicksburg, Mississippi, USA, 1990.

Wanninkhof, R. and Bliven, L. F.: Relationship between gas exchange, wind speed and radar backscatter in large wind wave tanks, J. Geophys. Res., 96(2), 2785-2796, 1991.

Woolf, D. K.: Bubbles and the air-sea transfer velocity of gases, Atmos.-Ocean, 31, 517-540, 1993.

Woolf, D. K.: Energy dissipation through wave breaking and the air-sea exchange of gases, in: Air-Water Gas Transfer, edited by: Jahne, B. and Monahan, E. C., AEON Verlag, Heidelberg, 185195, 1995.

Woolf, D. K.: Bubbles and their role in air-sea gas exchange, in: The Sea Surface and Global Change, edited by: Liss, P. S. and Duce, R. A., Cambridge University Press, 173-205, 1997.

Woolf, D. K., Leifer, I. S., Nightingale, P. D., Rhee, T. S., Bowyer, P., Caulliez, G., de Leeuw, G., Larsen, S. E., Liddicoat, M., Baker, J., and Andreae, M. O.: Modeling of bubble-mediated gas transfer: Fundamental principles and a laboratory test, J. Mar. Syst., 66, 71-91, 2007.

Woolf, D. K. and Thorpe, S. A.: Bubbles and the air-sea exchange of gases in near saturation conditions, J. Mar. Res., 49, 435-466, 1991.

Zhang, D. P. and Sunamura, T.: Conditions for the occurrence of vortices induced by breaking waves, Coastal Engineering in Japan, 332, 145-155, 1990.

Zappa, C. J., Asher, W. E., and Jessup, A. T.: Microscale wave breaking and air-water gas transfer, J. Geophys. Res., 106, 93859391, 2001. 